\title{
Inhibition of casein kinase II reduces TGF $\beta$ induced fibroblast activation and ameliorates experimental fibrosis
}

\author{
Yun Zhang, ${ }^{1}$ Clara Dees, ${ }^{1}$ Christian Beyer, ${ }^{1}$ Neng-Yu Lin, ${ }^{1}$ Alfiya Distler, ${ }^{1}$ Pawel Zerr, ${ }^{1}$ \\ Katrin Palumbo, ${ }^{1}$ Laura Susok, ${ }^{2}$ Alexander Kreuter, ${ }^{3}$ Oliver Distler, ${ }^{4}$ Georg Schett, ${ }^{1}$ \\ Jörg H W Distler ${ }^{1}$
}

\begin{abstract}
Handling editor Tore K Kvien
- Additional material is

published online only. To view please visit the journal online (http://dx.doi.org/10.1136/ annrheumdis-2013-204256).

${ }^{1}$ Department of Internal Medicine 3 and Institute for Clinical Immunology, University of Erlangen-Nuremberg, Erlangen, Germany

${ }^{2}$ Department of Dermatology, Ruhr-University Bochum,

Bochum, Germany

${ }^{3}$ Department of Dermatology,

Venereology, and Allergology, HELIOS St. Elisabeth Hospital Oberhausen, Germany ${ }^{4}$ Rheumaklinik, University Hospital Zurich, Zurich, Switzerland
\end{abstract}

\section{Correspondence to} Dr Jörg Distler, Department of Medicine 3 and Institute for Clinical Immunology, University of Erlangen-Nuremberg, Ulmenweg 18, Erlangen D-91054, Germany; Joerg.distler@uk-erlangen.de

Received 9 July 2013 Revised 10 December 2013 Accepted 21 December 2013 Published Online First 14 January 2014

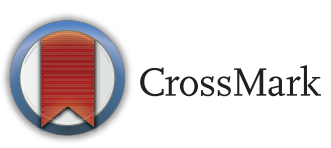

To cite: Zhang Y, Dees $C$, Beyer $C$, et al. Ann Rheum Dis 2015;74:936-943.

\section{ABSTRACT}

Objectives Casein kinase II (CK2) is a constitutively active serine/threonine protein kinase that plays a key role in cellular transformation and tumorigenesis. The purpose of the study was to characterise whether CK2 contributes to the pathologic activation of fibroblasts in patients with SSC and to evaluate the antifibrotic potential of CK2 inhibition.

Methods Activation of CK2, JAK2 and STAT3 in human skin and in experimental fibrosis was analysed by immunohistochemistry. CK2 signalling was inhibited by the selective CK2 inhibitor 4, 5, 6, 7-Tetrabromobenzotriazole (TBB). The mouse models of bleomycin-induced and TGF $\beta$ receptor I (TBR)-induced dermal fibrosis were used to evaluate the antifibrotic potential of specific CK2 inhibition in vivo.

Result Increased expression of CK2 was detected in skin fibroblasts of SSC patients. Inhibition of CK2 by TBB abrogated the TGF $\beta$-induced activation of JAK2/STAT3 signalling and prevented the stimulatory effects of TGF $\beta$ on collagen release and myofibroblasts differentiation in cultured fibroblasts. Inhibition of CK2 prevented bleomycininduced and TBR-induced skin fibrosis with decreased dermal thickening, lower myofibroblast counts and reduced accumulation of collagen. Treatment with TBB also induced regression of pre-established fibrosis. The antifibrotic effects of TBB were accompanied by reduced activation of JAK2/STAT3 signalling in vivo.

Conclusions We provide evidence that CK2 is activated in SSC and contributes to fibroblast activation by regulating JAK2/STAT3 signalling. Inhibition of CK2 reduced the profibrotic effects of TGF $\beta$ and inhibited experimental fibrosis. Targeting of CK2 may thus be a novel therapeutic approach for SSc and other fibrotic diseases.

\section{INTRODUCTION}

Systemic sclerosis (SSc) is a chronic fibrotic disease of unknown aetiology that affects the skin and various internal organs. SSc is characterised by an uncontrolled activation of fibroblasts, which release excessive amounts of extracellular matrix. ${ }^{1}$ The accumulation of extracellular matrix proteins disrupts tissue architecture and causes high morbidity and mortality. ${ }^{2}$ Transforming growth factor- $\beta$ (TGF $\beta$ ) has been characterised as a key mediator of fibroblast activation in SSc and other fibrotic diseases. ${ }^{3}$ However, the precise molecular mechanisms and the intracellular signalling cascades that mediate the TGF $\beta$-induced activation of fibroblasts are still incompletely understood.

Casein kinase II (CK2) is a constitutively active serine/threonine protein kinase. ${ }^{4}$ CK2 consists of a tetrameric complex with two regulatory CK2 $\beta$ subunits and two catalytic subunits ( $\alpha$ and/or $\left.\alpha^{\prime}\right)$ in a homozygous or heterozygous composition. ${ }^{5} \mathrm{CK} 2$ is crucial for cell and tissue homeostasis by regulating proliferation, differentiation, apoptosis and senescence. ${ }^{6}$ There is mounting evidence indicating that deregulation of CK2 is involved in cellular transformation and cancer. Abnormally high expression of CK2 was detected in different tumours, including mammary, ${ }^{7}$ prostate, ${ }^{8}$ lung, ${ }^{9}$ head and neck ${ }^{10}$ and kidney cancers. ${ }^{5} 11$ Moreover, inhibition of CK2 demonstrated potent antitumor effects in several preclinical models. ${ }^{12} 13$ These results stimulated development of novel CK2 inhibitors with tetrabromobenzotriazole (TBB) as a lead compound for novel CK2 inhibitors. ${ }^{14}$ One of those novel CK2 inhibitors have recently entered first clinical trials (http://clinicaltrials.gov; NCT00891280 and NCT01199718).

Of particular interest, CK2 has recently been discovered as a novel interaction partner of JAK proteins. ${ }^{15}$ Based on the recent identification of JAK2 as a crucial downstream target of TGF $\beta$ signalling in fibroblasts, ${ }^{16}$ we hypothesised that CK2 may be a novel regulator of fibroblast activation in SSc. Here, we aimed to analyse CK2 activation in SSc, to investigate its role in fibroblast activation and to characterise the antifibrotic potential of CK2 inhibitors in preclinical models of SSc.

\section{MATERIAL AND METHODS}

\section{Patient samples and fibroblast culture}

Skin biopsies were obtained from involved skin at the volar aspect of the forearm of 18 patients with SSc. All patients fulfilled the criteria for SSc as defined by LeRoy et al. ${ }^{17} 18$ The study included 13 female and 5 male SSc patients. The median age was 51 years, ranging from 20 to 71 , and median disease duration was 6 years, ranging from 1 to 13 years. Seven patients had limited cutaneous disease, 11 from the diffuse disease subtype. Prior to biopsy, patients had not received any disease-modifying antirheumatic drug treatment. Seventeen age-matched and sex-matched healthy volunteers served as controls. Fibroblast cultures were generated as previously described. ${ }^{19-21}$ 


\section{Inhibition of CK2 signalling and TGF $\beta$ signalling}

For pharmacologic blockade of CK2 signalling, we used the cellpermeable selective CK2 inhibitor 4,5,6,7-(TBB) (Tocris, Ellisville, Missouri , USA). Dermal fibroblasts were incubated with TBB in concentrations of $1 \mu \mathrm{M}$ and $5 \mu \mathrm{M}$. In selected experiments, recombinant human TGF $\beta(10 \mathrm{ng} / \mathrm{mL})$ (R\&D Systems, Wiesbaden, Germany) was added $1 \mathrm{~h}$ after TBB.

For TGF $\beta$ inhibition, we used orally active ATP-competitive transforming growth factor $\beta$ receptor 1 (TGF $\beta R I)$ inhibitor 2-(5-Chloro-2-fluorophenyl)-4-((4-pyridyl) amino)pteridine SD 208 (Tocris, Ellisville, Missouri , USA) at a doses of $20 \mathrm{mg} / \mathrm{kg}$ twice a day.

\section{Quantitative real-time PCR (qPCR)}

Total RNA was isolated with a NucleoSpin RNA II extraction system (Machery-Nagel, Dueren, Germany) and reverse transcribed into complementary DNA (cDNA), as previously described. $^{22}{ }^{23}$ Gene expression was quantified by real-time PCR using the MxPro 3005P QPCR System (Agilent Technologies, Santa Clara, California, USA). Specific primer pairs for each gene were designed with Primer3 software. ${ }^{24} 25$ The sequences of the human CK2 $\alpha$, CK2 $2 \alpha^{\prime}$, CK2 $\beta$, collagen $1 \mathrm{a} 1$, collagen $1 \mathrm{a} 2$ and $\alpha$ smooth muscle actin ( $\alpha \mathrm{SMA}$ ) primers are summarised in online supplementary table $S 1$. $\beta$-actin assay primer (Applied Biosystems, Darmstadt, Germany) was used to normalise for the amounts of loaded cDNA. Dissociation curve analysis, samples without enzyme in reverse transcription (non-RT controls), and no-template controls were used as negative controls to exclude genomic DNA contamination and formation of primer dimers. Differences were calculated with the threshold cycle $(\mathrm{Ct})$ and the comparative $\mathrm{Ct}$ method for relative quantification.

\section{Immunohistochemical analyses}

Immunohistochemical analysis of paraffin-embedded sections was performed as previously described. ${ }^{26-28}$ Cells positive for $\alpha$-SMA in murine sections were detected by incubation with anti- $\alpha$-SMA monoclonal antibodies (clone 1A4; Sigma-Aldrich, Steinheim, Germany). The levels of CK2 $\alpha$ and CK2 $\beta$ in patients with SSc and controls were assessed by staining with anti-CK2 $\alpha$ (Epitomics, Burlingame, California, USA) and CK2 $\beta$ antibodies (Santa Cruz, Biotechnology, California, USA) at $4^{\circ} \mathrm{C}$ overnight. Fibroblasts were identified by staining with anti-prolyl-4-hydroxylase- $\beta$ monoclonal antibodies (Acris Antibodies, Herford, Germany). ${ }^{29}$ Irrelevant isotype antibodies in the same concentration were used as controls. Antibodies labelled with horseradish peroxidase (Dako, Hamburg, Germany), Alexa Fluor 488, and Alexa Fluor 594 (both Invitrogen, Carlsbad, California, USA) were used as secondary antibodies. The binding of $\alpha$ SMA, pJAK2 (Tyr1007/1008) (Epitomics, Burlingame, California, USA) and pSTAT3 monoclonal antibodies (Cell Signaling Technology, Danvers, Massachusetts, USA) was visualised with diaminobenzidine peroxidase substrate solution (Sigma-Aldrich). Semiquantitative scoring of the staining was performed as follows: the epidermis, fibroblasts (spindleshaped single cells in the dermis) and vessels were scored separately. No staining was scored as 0 , faint staining or staining in very few cells was scored as 1 , moderate staining was scored as 2 and very intense staining in the majority of cells was scored as 3 .

\section{Western blot analysis}

PVDF membranes were incubated with anti-human CK2 $\alpha$ antibodies (Epitomics), CK2 $\beta$ antibodies (Santa Cruz) pJAK2 antibodies (Epitomics), JAK2 antibodies (Abcam, San Antonio,
Texas, USA), pSTAT3 antibodies (Cell Signaling Technology, Danvers, Massachusetts, USA), pSmad3 antibodies (Cell Signaling Technology, Danvers, Massachusetts, USA), Smad3 antibodies (Millipore, Billerica, Massachusetts, USA) or STAT3 antibodies (Cell Signaling Technology). Horseradish peroxidaseconjugated antibodies (Dako) were used as secondary antibodies. Equal loading of proteins was confirmed by visualisation of $\beta$-actin (Sigma-Aldrich).

\section{Analyses of myofibroblast differentiation}

Serum-starved cells were stimulated with TGF $\beta(10 \mathrm{ng} / \mathrm{mL})$ for $24 \mathrm{~h}$. After fixation and blocking, fibroblasts were incubated with mouse anti- $\alpha$-SMA monoclonal antibodies (clone 1A4; SigmaAldrich).$^{30}$ Fibroblasts incubated with irrelevant isotype antibodies were used as controls. Alexa Fluor 488 goat antimouse antibodies (Invitrogen, Carlsbad, California, USA) served as secondary antibodies. Stress fibres were stained with rhodamine-conjugated phalloidin (Invitrogen). ${ }^{16}$ Counterstaining of nuclei was performed with DAPI (Santa Cruz Biotechnology). The fluorescence intensity was quantified using ImageJ software V.1.44.

\section{Mouse models of fibrosis}

Two different mouse models of SSc were used, bleomycininduced skin fibrosis and fibrosis induced by overexpression of a constitutively active TGF $\beta$ receptor I (AdTBR). ${ }^{31}$ Bleomycininduced dermal fibrosis was induced in 6-week-old female FVB mice (Charles River) by local injection of bleomycin for 28 days. $^{32-35}$ Control mice were injected with $0.9 \% \mathrm{NaCl}$, the solvent for bleomycin. To evaluate the effects of CK2 inhibition, mice were treated with TBB in doses of $2.5 \mathrm{mg} / \mathrm{kg} /$ day or $10 \mathrm{mg} / \mathrm{kg} /$ day by intraperitoneal injection. Seven mice were analysed in each group.

For established bleomycin-induced fibrosis, mice were injected with bleomycin for up to 6 weeks ${ }^{35-38}$ and treatment with TBB was initiated only after 3 weeks of prechallenge with bleomycin. To assess the extent of fibrosis before the onset of treatment, one group of mice was injected with $0.9 \% \mathrm{NaCl}$ for 3 weeks, followed by injections of $0.9 \% \mathrm{NaCl}$ for another 3 weeks. Six mice were analysed in each group.

AdTBR mediated fibrosis was induced as described. ${ }^{18} 39$ Briefly, $6.67 \times 10^{7}$ infectious units of replication-deficient, attenuated type $\mathrm{V}$ adenoviruses overexpressing TBR were injected intracutaneously. Mice injected with adenoviruses carrying a LacZ reporter gene served as controls. Six mice were analysed in each group.

The effect of CK2 inhibition on experimental dermal fibrosis was analysed by quantification of dermal thickening, myofibroblasts counts and hydroxyproline content as described previously. 334041

\section{Statistical analysis}

Data are expressed as median with IQR, and differences between the groups were tested for their statistical significance by non-parametric Mann-Whitney $U$ test. $p$ Values less than 0.05 were considered significant.

\section{RESULTS}

\section{CK2 $\alpha$ and CK2 $\beta$ expression is increased in SSc}

We first analysed the expression of CK2 in skin sections of SSc patients and matched healthy volunteers.CK2 $\alpha$ and CK2 $\beta$ (figure 1A) showed more intense staining in SSc skin compared to healthy individuals with prominent expression in spindleshaped cells in the dermis. Double staining with the fibroblast marker prolyl-4-hydroxylase $\beta$ confirmed that all SSc fibroblasts 

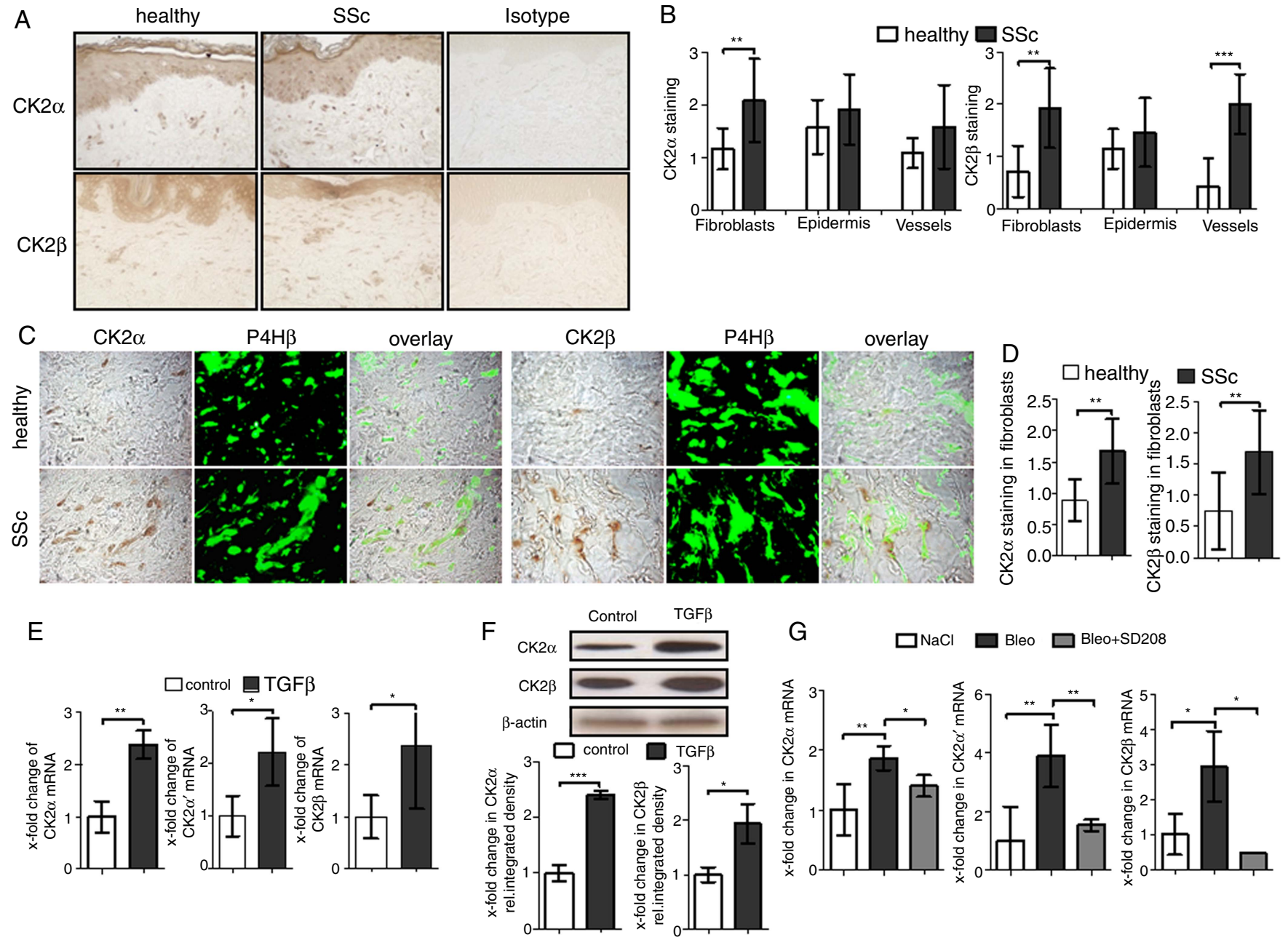

Figure 1 The expression of CK2 is increased in SSc fibroblasts. (A) Expression of CK2 $\alpha$ (upper row) and CK2 $\beta$ (lower row) was detected by immunohistochemistry in the skin biopsies of healthy volunteers and SSC patients. Representative examples of SSC patients and healthy individuals are shown at 400 -fold magnification ( $n=8$ each). (B) Semiquantitative analysis of staining confirmed that the levels of CK2 were significantly upregulated in fibroblasts in SSC skin compared to fibroblasts in the skin of healthy individuals. (C) Double staining of CK2 $\alpha$ or CK2 $\beta$ with the fibroblast marker prolyl-4-hydroxylase $\beta(\mathrm{P} 4 \mathrm{H} \beta)$. Representative images of SSc patients and healthy individuals are shown at 1000 -fold magnification ( $n=8$ each). (D) Semiquantitative analysis of CK2 expression in P4H $\beta$-fibroblasts in SSc patients and controls. (E) Stimulation with TGF $\beta$ upregulated the mRNA levels of $C K 2 \alpha, C K 2 \alpha^{\prime}$ and CK2 $\beta$ in cultured fibroblasts from healthy individuals $(n=4)$ and TGF $\beta$ stimulated fibroblasts. (F) Stimulation of healthy dermal fibroblasts with TGF $\beta$ increased the levels CK2 $\alpha$ and CK2 $\beta$ protein $(n=4)$. (G) Treatment with the selective TGF $\beta R$ inhibitor SD208 prevents the increases of CK2 $\alpha$, CK2 $\alpha^{\prime}$ and CK2 $\beta$ mRNA by bleomycin in murine skin $(n=6)$.

express high levels of CK $2 \alpha$ and CK2 $\beta$, whereas only a minority of fibroblasts stained positive for CK2 in sections from healthy individuals (figures 1C,D). Semiquantitative analysis of the stainings confirmed that the levels of CK $2 \alpha$ and CK2 $\beta$ were significantly upregulated in fibroblasts in SSc patients (figure 1B).

\section{CK2 $\alpha$ and CK2 $\beta$ are upregulated in a TGF $\beta$-dependent manner}

Aberrant TGF $\beta$ signalling is a major hallmark of SSc and other fibrotic diseases. To investigate whether TGF $\beta$ stimulates CK2 signalling, we incubated dermal fibroblasts with recombinant TGF $\beta$. The mRNA levels of CK $2 \alpha, \mathrm{CK} 2 \alpha^{\prime}$ and CK $2 \beta$ increased significantly after TGF $\beta$ stimulation (figure 1E). Stimulation with TGF $\beta$ also upregulated the protein levels of CK2 $\alpha$ and CK2 $\beta$ by $58 \%(\mathrm{p}=0.0001)$ and $48 \%(\mathrm{p}=0.0139)$, respectively (figure $1 \mathrm{~F}$ ). In murine skin, the mRNA levels of CK2 $\alpha$, CK2 $\alpha^{\prime}$ and CK2 $\beta$ significantly increased upon standardised challenge with the profibrotic agent bleomycin (figure 1G). However, treatment with the selective TGFßRI inhibitor SD208 prevented the induction of CK $2 \alpha-$, CK $2 \alpha^{\prime}$ - and CK $2 \beta$ mRNA by bleomycin (figure $1 \mathrm{G}$ ). Taken together, these results suggested that CK2 is overexpressed in a TGF $\beta$-dependent manner in SSc.

\section{Inhibition of CK2 prevents myofibroblast differentiation and decreases the release of collagen in fibroblasts}

We wondered whether CK2 might be required for the profibrotic effects of TGF $\beta$. We first investigated the effects of CK2 inhibition by the selective CK2 inhibitor 4,5,6,7- TBB on myofibroblast differentiation. Myofibroblasts can be detected by the increased expression of $\alpha$-SMA and formation of stress fibres. CK2 inhibition prevented TGF $\beta$-induced myofibroblast differentiation, but had little effect on the basal levels of $\alpha$-SMA and stress fibres. Incubation with TBB reduced the TGF $\beta$-induced upregulation of $\alpha$-SMA mRNA by $68 \%(p=0.0284)$, the induction of $\alpha$-SMA protein by $38 \%(\mathrm{p}=0.0280)$, and the formation of stress fibres by $55 \%$ compared to TGF $\beta$ stimulated, mocktreated cells $(\mathrm{p}=0.0064)$ (figure $2 \mathrm{~A})$. 
A

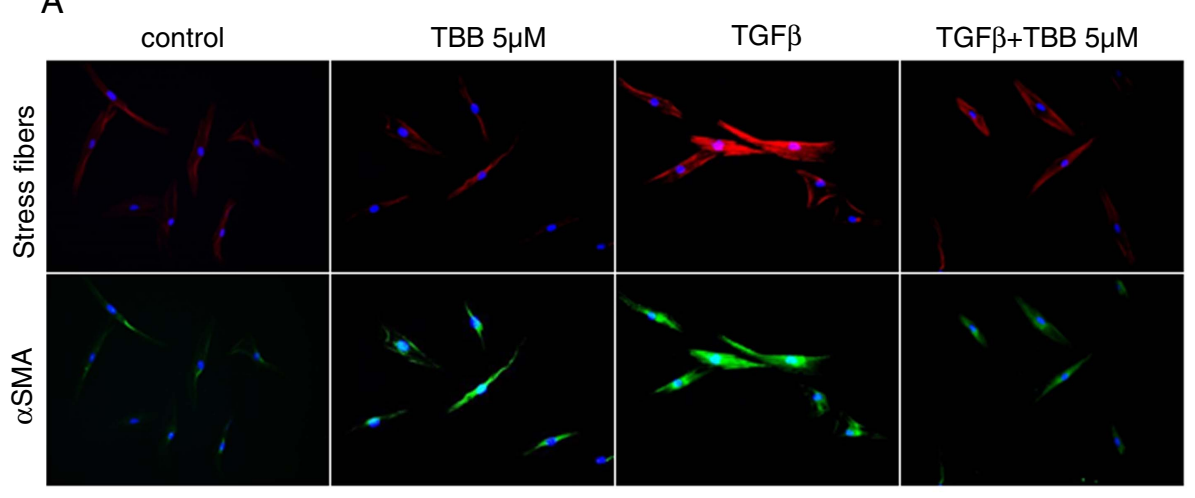

B

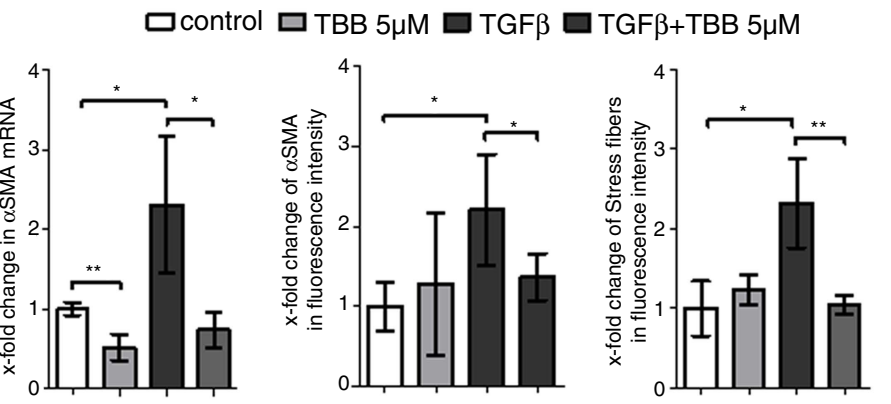

$\square$ control $\square$ TBB $1 \mu \mathrm{M} \quad \square$ TBB $5 \mu \mathrm{M}$ $\square$ TGF $\quad \square$ TGF $\beta+$ TBB $1 \mu \mathrm{M} \quad \square$ TGF $\beta+$ TBB $5 \mu \mathrm{M}$
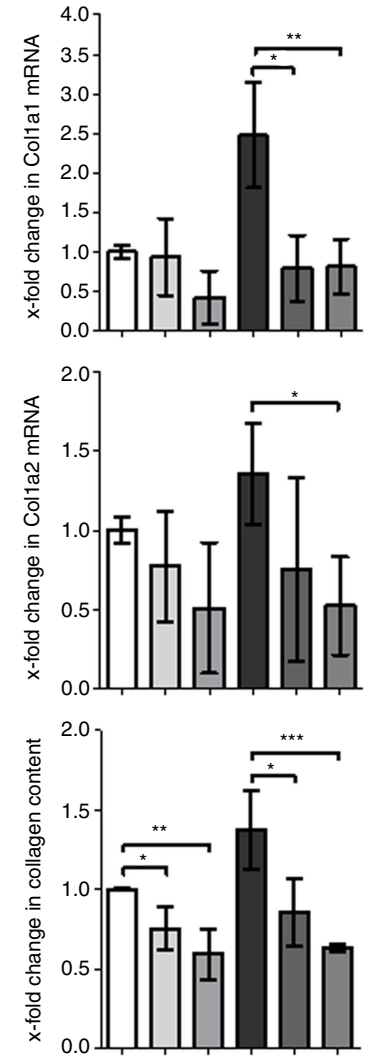

Figure 2 Inhibition of CK2 prevents myofibroblast differentiation and decreases the release of collagen in vitro. (A) Incubation with the CK2 inhibitor Tetrabromobenzotriazole (TBB) reduced the stimulatory effects of TGF $\beta$ on $\alpha$-smooth muscle actin ( $\alpha$-SMA) mRNA and protein production and prevented the formation of stress fibres $(n=4$ each). Representative images of fibroblasts are shown at 200-fold magnification. (B) Incubation with TBB dose-dependently reduced the mRNA levels of col1a1, col1a2 and prevented the release of collagen protein from TGF $\beta$-stimulated fibroblasts ( $n=4$ each).

We next analysed the effect of CK2 inhibition on the release of collagen. Incubation with TBB reduced the stimulatory effects of TGF $\beta$ in a dose-dependent manner. The mRNA levels of colla1 and col1a2 decreased by $88 \%(\mathrm{p}=0.0083)$ and $84 \%$ $(\mathrm{p}=0.0219)$, respectively, compared with mock-treated fibroblasts stimulated with TGF $\beta$ (figure 2B). Consistently, TBB reduced the TGF $\beta$-induced release of collagen protein by $82 \%$ $(\mathrm{p}=0.0042)$ (figure 2B).

\section{Inhibition of CK2 suppresses TGF $\beta$-induced JAK2-STAT3 activation}

JAK2 and its downstream mediator STAT3 have recently been identified as intracellular mediators of the pro-fibrotic effects of TGF $\beta$ in fibroblasts. To investigate whether CK2 regulates JAK2/ STAT3 activation in fibroblasts, we analysed the phosphorylation and subcellular localisation of JAK2 and STAT3 in response to TGF $\beta$ and TBB. Stimulation with TGF $\beta$ induced phosphorylation of JAK2 in the cytoplasmatic fraction, but did not alter the total levels of JAK2 or induce its nuclear translocation. TGF $\beta$ also increased the nuclear levels of phosphorylated and thereby activated STAT3. Co-incubation with TBB completely prevented the TGF $\beta$-induced accumulation of phosphorylated JAK2 (figure 3A). Additionally, TBB also abrogated the nuclear accumulation of phosphorylated STAT3 (figure 3B). These data suggest that CK2 is essentially required for TGF $\beta$-induced activation of
A

Cytoplasm

Control TBB TGF $\beta$ TGF $\beta+$ TBB
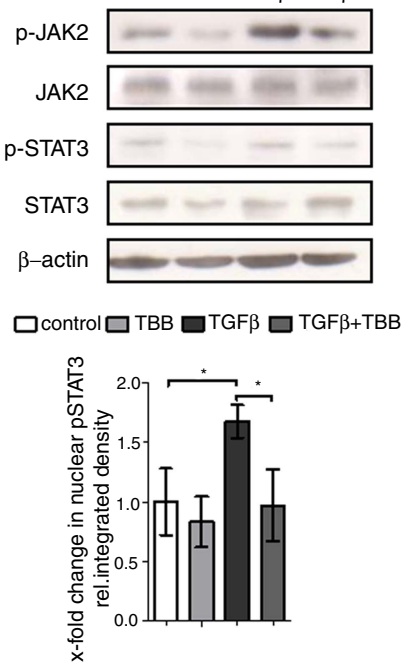

B

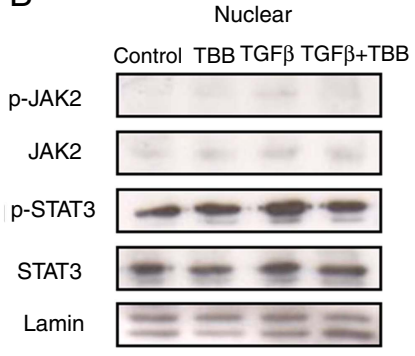

$\square$ control $\square$ TBB $\square$ TGFB $\square$ TGF $\beta+$ TBB

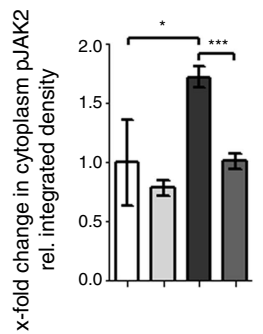

Figure 3 Inhibition of CK2 suppresses TGF $\beta$-induced JAK2-STAT3 signalling. Stimulation of fibroblasts with TGF $\beta$ increased the levels of pJAK2 in the cytoplasm (A) and PSTAT3 in nucleus (B) without altering the total levels of JAK2 and STAT3. Inhibition of CK2 by Tetrabromobenzotriazole (TBB) prevented the TGF $\beta$-induced phosphorylation of JAK2 and STAT3 (A and B). ( $n=3$ each). 
JAK2/STAT3 in SSc fibroblasts. By contrast, inhibition of CK2 by TBB did not prevent the TGF $\beta$-induced phosphorylation of Smad3, indicating that CK2 may not regulate canonical TGF $\beta$ / Smad signalling (see online supplementary figures S1A,B).

\section{Inhibition of CK2 prevents bleomycin-induced skin fibrosis}

We next investigated whether inhibition of CK2 can prevent fibrosis in murine models of SSc. First, we examined the effects of CK2 in the mouse model of bleomycin-induced skin fibrosis. Injection of bleomycin induces prominent skin fibrosis resembling early, inflammatory stages of SSc. ${ }^{31}$ Consistent with the findings in human SSc, the levels of $\mathrm{CK} 2 \alpha$ and CK2 $\beta$ were increased in bleomycin-challenged mice compared to $\mathrm{NaCl}$-treated mice (see online supplementary figures S2A,B), demonstrating that bleomycin-induced skin fibrosis is a suitable model to study CK2 signalling in SSc.

Treatment with TBB at a dose of $2.5 \mathrm{mg} / \mathrm{kg}$ daily, significantly reduced dermal thickening $(p=0.0362)$ compared with vehicle- treated, bleomycin-challenged mice (figures 4A,B). At higher dosages of $10 \mathrm{mg} / \mathrm{kg}$ daily, dermal thickening was further decreased $(p<0.0001)$ (figure 4A,B). The hydroxyproline content decreased dose-dependently by up to $47 \%(\mathrm{p}=0.0002)$ at $10 \mathrm{mg}$ $\mathrm{kg}$ (figure 4B). The differentiation of resting fibroblasts into myofibroblasts was also significantly reduced by TBB $(p=0.0002)$ (figure 4B). Consistent with our findings on the molecular mechanism in vitro, the antifibrotic effects of CK2 inhibition were paralleled by impaired JAK2/STAT3 activation. Treatment with TBB prevented the accumulation of pJAK2 and pSTAT3 in bleomycin-challenged mice and reduced the levels of pJAK2 and pSTAT3 to that of non-fibrotic control mice (figure 4C,D).

\section{CK2 inhibition ameliorates TBR-induced fibrosis}

We further evaluated the antifibrotic effects of CK2 inhibition in the mouse model of TBR-induced fibrosis. Overexpression of TBR increased the expression of CK $2 \alpha$ and CK $2 \beta$ and induced prominent dermal thickening and accumulation of collagen compared to
A

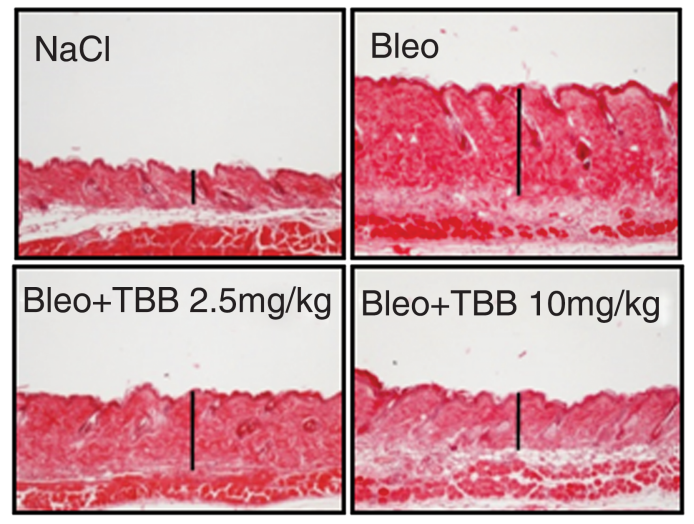

B

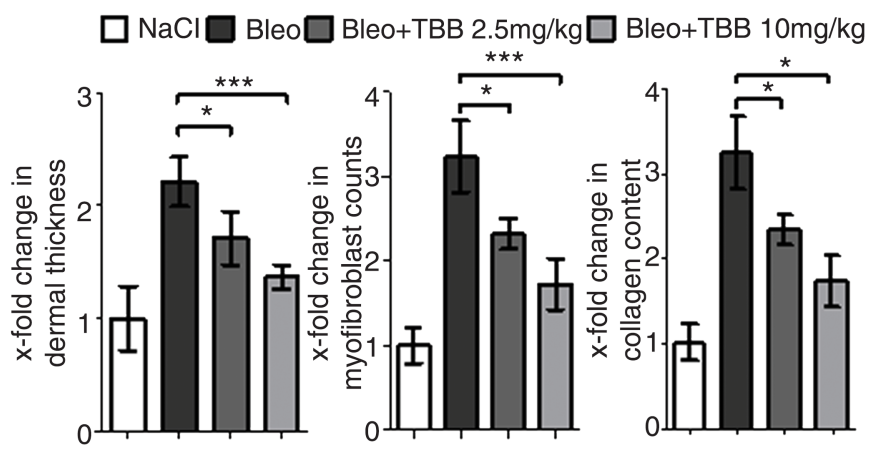

C

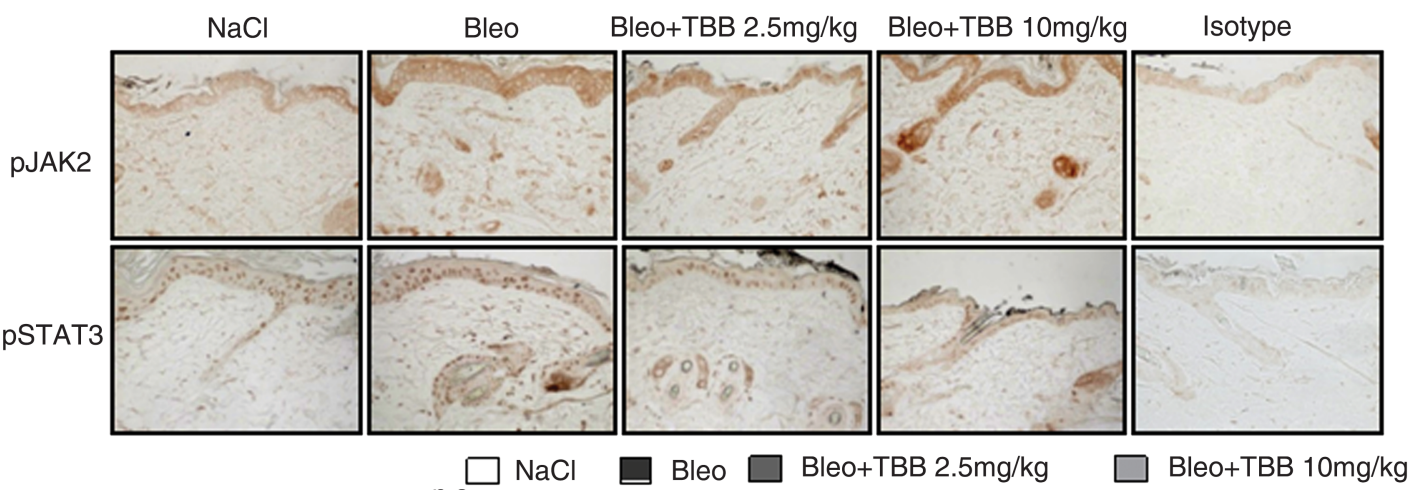

D
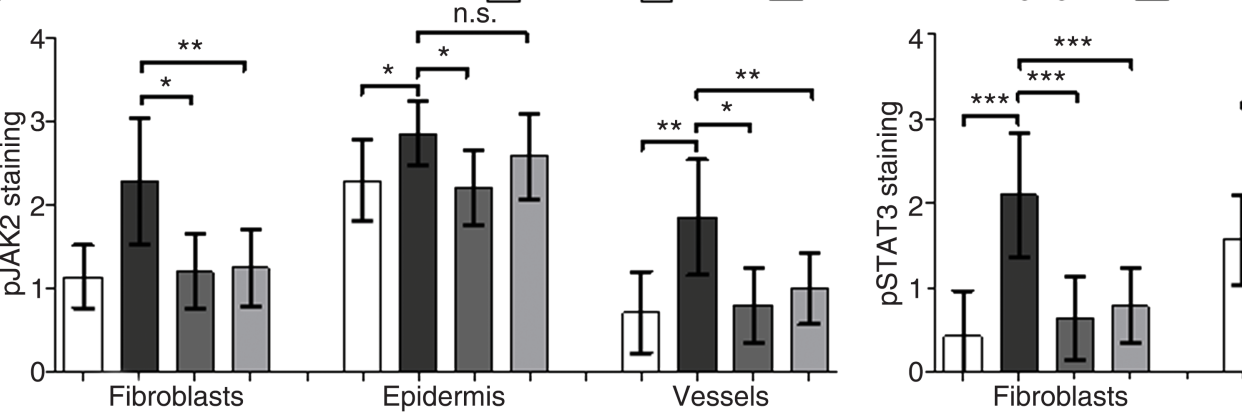

Fibroblasts

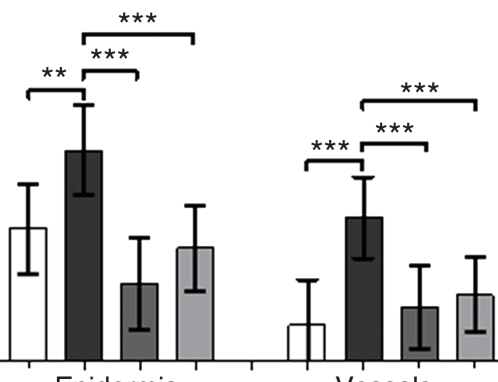

Figure 4 CK2 inhibition prevents bleomycin-induced fibrosis and suppresses JAK2 STAT3 signalling. (A) Representative H\&E-stained skin sections from control mice injected with $0.9 \% \mathrm{NaCl}(n=6)$, bleomycin-challenged mice receiving vehicle treatment $(n=6)$, mice injected with bleomycin and treated with Tetrabromobenzotriazole (TBB) at doses of $2.5 \mathrm{mg} / \mathrm{kg}$ daily, or $10 \mathrm{mg} / \mathrm{kg}$ daily $(\mathrm{n}=6$ each) are shown at 100 -fold magnification. (B) Treatment with TBB reduced bleomycin-induced dermal thickening and decreased the hydroxyproline content and the myofibroblast counts. (C) Inhibition of CK2 prevented the bleomycin-induced activation of JAK2/STAT3 signalling and reduced the levels of pJAK2 and pSTAT3 in fibrotic skin. Representative images are shown at 400-fold magnification. (D) Semiquantitative analysis of staining confirmed that the levels of pJAK2 and pSTAT3 were significantly downregulated in fibroblasts upon treatment with TBB. 
LacZ control mice (see online supplementary figures S3A,B). Similarly to its effect in bleomycin model of SSc, treatment with TBB reduced dermal thickening by $38 \%$ in TBR-induced fibrosis compared to vehicle-treated TBR mice $(\mathrm{p}<0.0001)$ (figure 5A,B). The hydroxyproline content and the number of myofibroblasts were also significantly reduced upon inhibition of CK2 (figure 5B). Consistent with these antifibrotic effects, TBB treatment completely prevented activation of JAK2/STAT3 signalling induced by overexpression of TBR (figure 5C,D).

\section{Inhibition of CK2 induces regression of pre-established bleomycin-induced skin fibrosis}

We next analysed whether pharmacologic inhibition of CK2 is also effective in therapeutic settings, when treatment is initiated after fibrosis has already been established. Prolonged injections of bleomycin induced progressive skin fibrosis. Treatment with TBB for the last 3 weeks did prevent progression of bleomycin-induced skin fibrosis, and also reduced the dermal thickness, the hydroxyproline content and the myofibroblast counts ( $p<0.0001$ for all outcomes) to below the levels of mice injected with bleomycin for only 3 weeks (pretreatment levels), demonstrating that TBB does prevent experimental fibrosis, and can also induce regression of pre-established bleomycin-induced fibrosis (see online supplementary figures S4A,B).

\section{DISCUSSION}

Aberrant TGF $\beta$ signalling is a hallmark of SSc and other fibrotic diseases. However, the molecular mechanisms underlying the persistent activation of TGF $\beta$ signalling are incompletely understood. Here, we demonstrated that TGF $\beta$ stimulates the expression of $\mathrm{CK} 2 \alpha$ and $\mathrm{CK} 2 \beta$. TGF $\beta$ upregulates $\mathrm{mRNA}$ and protein levels of CK $2 \alpha$ and CK $2 \beta$ in fibroblasts, whereas inhibition of TGF $\beta$ signalling prevents the induction of CK2 subunits in fibrotic skin. The activation of CK2 in turn is required for the pro-fibrotic effects of TGF $\beta$ on fibroblasts. Inhibition of CK2 ameliorates the pro-fibrotic effects of TGF $\beta$ and reduces the release of extracellular matrix in vitro and in vivo. The induction of CK2 by TGF $\beta$ may thus enhance the pro-fibrotic effects of TGF $\beta$, thereby creating a vicious cycle that contributes to aberrant TGF $\beta$ signalling and persistent fibroblast activation in SSc and in other fibrotic diseases.

We demonstrate that CK2 does not modify canonical, Smad-dependent TGF $\beta$ signalling, but rather regulates TGF $\beta$-induced activation of JAK2. JAK2 has recently been
A
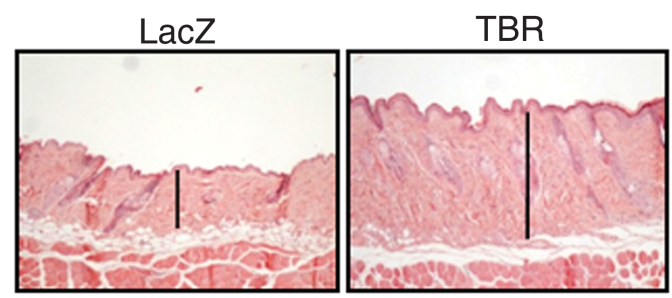

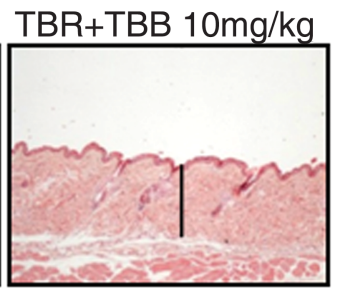

B

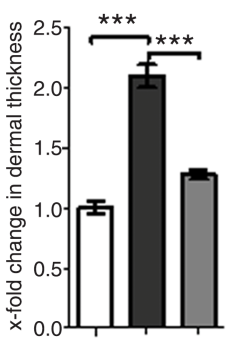

口LacZ DTBR 口TBR + TBB 10mg/kg

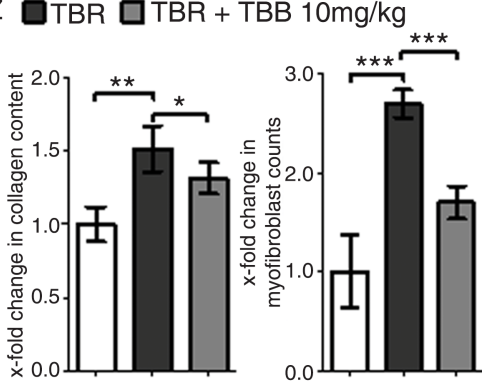

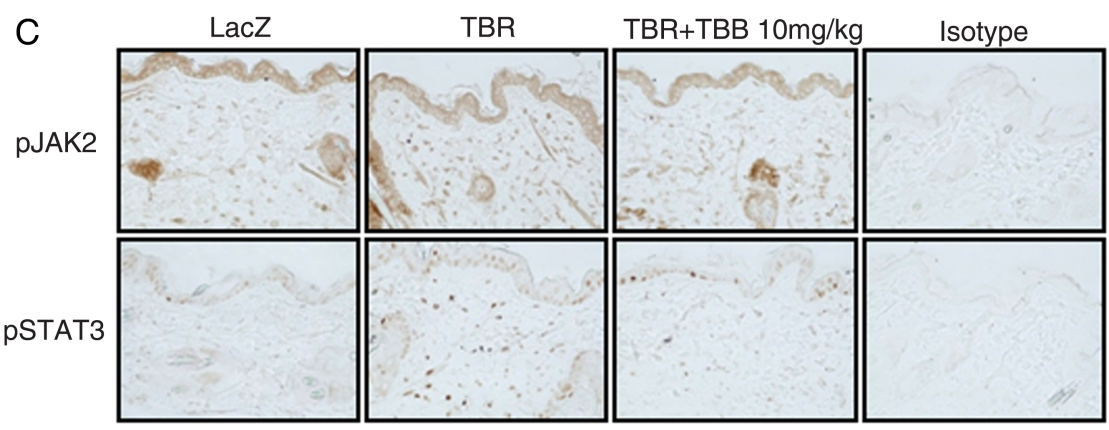

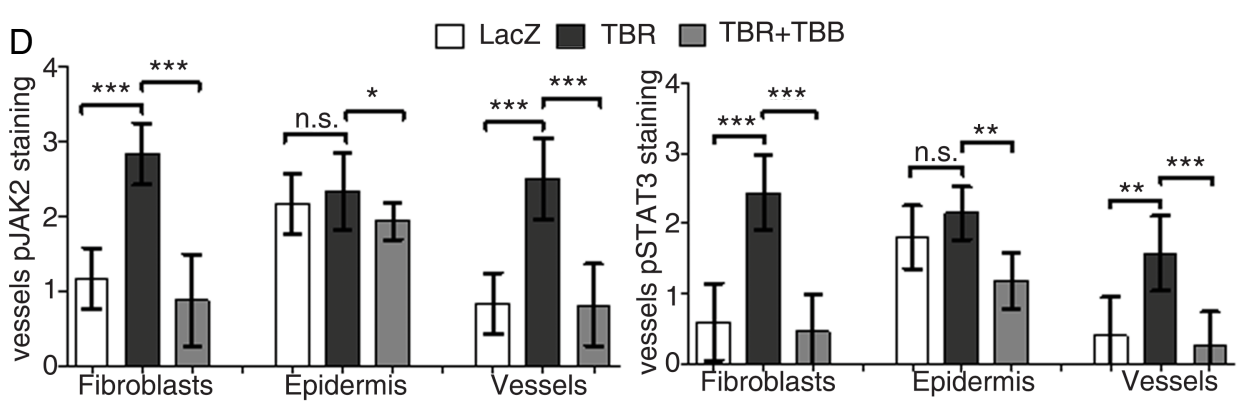

Figure 5 CK2 inhibition prevents TBR-induced fibrosis and suppresses JAK2 STAT3 signalling. (A) Representative H\&E-stained skin sections from control mice injected with LacZ-AAV, mice injected with TBR-AAV receiving vehicle treatment and mice injected with TBR-AAV and treated with TBB are shown at 100-fold magnification ( $n=6$ for all groups). (B) Treatment with Tetrabromobenzotriazole (TBB) reduced TBR-induced dermal thickening, collagen accumulation and myofibroblast differentiation versus vehicle-treated TBR-AAV mice. (C) Immunohistochemistry demonstrated an up-regulation of pJAK2 and PSTAT3 in the skin of TBR-AAV mice, which was completely prevented by TBB treatment. Representative images are shown at 400-fold magnification. (D) Semiquantitative analysis of staining demonstrated decreased levels of pJAK2 and pSTAT3 in fibroblasts of TBR mice treated with TBB compared to vehicle-treated TBR-AAV mice. 
identified as novel intracellular mediator of TGF $\beta$ signalling. JAK2 is activated in SSc in a TGF $\beta$-dependent manner, and pharmacologic or genetic inactivation of JAK2 reduces the profibrotic effects of TGF $\beta$. Although the precise mechanisms are unknown, we demonstrate here that inhibition of CK2 prevents phosphorylation of JAK2, thereby reducing activation and nuclear translocation of its downstream mediator STAT3 in cultured human fibroblasts and in two mouse models of SSc. Consistent with these findings, CK2 inhibitors have recently been shown to suppress the constitutive autophosphorylation of mutated JAK2V617F and induce apoptosis in cells from patients with polycythaemia vera. ${ }^{15}$

The potent antifibrotic effects of CK2 inhibitors in vitro and in different mouse models in vivo indicated that CK2 may also positively regulate other pro-fibrotic pathways in addition to JAK2 signalling. Indeed, accumulating evidence from the cancer field demonstrates that CK2 can enhance the stability of $\beta$-catenin, thus facilitating canonical Wnt signalling and tumorigenesis. ${ }^{42}$ However, further studies are required to investigate the effect of CK2 inhibitors on Wnt signalling in fibrotic diseases and to analyse the relative contribution of targeting JAK2- and Wnt signalling to the antifibrotic effects of CK2 inhibitors.

We demonstrated that CK2 inhibitors exert potent antifibrotic effects in two different mouse models in pharmacologically relevant doses. The CK2 inhibitor TBB effectively reduced the histological features of fibrosis, decreased collagen content and prevented the differentiation of resting fibroblasts into myofibroblasts in the mouse models of bleomycin-induced and TBR-induced fibrosis. Of note, TBB was well tolerated, and toxic effects were neither observed clinically nor on necroscopy. Both mouse models mimic different aspects and different stages of SSc. The mouse model of bleomycin-induced skin fibrosis resembles early, inflammatory stages of SSc with leukocyte infiltration and subsequent activation of fibroblasts by leukocytederived mediators. By contrast, the TBR model resembles later, non-inflammatory stages of SSc with endogenous activation of SSc fibroblasts and persistently activated TGF $\beta$ signalling. The potent antifibrotic effects of TBB in those models indicate that CK2 inhibition may be effective in the inflammatory subset of SSc patients as well as in SSc patients in later, less inflammatory stages. These findings could have translational implications, because first CK2 inhibitors recently entered clinical trials in patients with different malignancies (http://clinicaltrials.gov; NCT00891280 and NCT01199718). In addition to the more advanced programmes with ATP-competitive compounds, several new, non-ATP-competitive inhibitors are currently in clinical development. ${ }^{43}$ However, further preclinical evaluation of CK2 in fibrotic diseases is warranted. This should include analyses of the antifibrotic effects of CK2 inhibitors in other organ systems, evaluation of the effects on established fibrosis and investigation of the role of CK2 on endothelial cells and on SSc-associated microvascular disease.

In summary, we demonstrated that TGF $\beta$ induces CK2 $\alpha$ and CK2 $\beta$, which are in turn required for the pro-fibrotic effects of TGF $\beta$. Inactivation of CK2 prevents the TGF $\beta$-induced activation of JAK2/STAT3 and significantly ameliorates fibrosis in different mouse models of SSc. These findings may have translational implications, as CK2 inhibitors were well tolerated in antifibrotic doses, and potent CK2 inhibitors are currently in clinical trials.

Acknowledgements We thank Katja Dreißigacker, Regina Kleinlein, Rosella Mancuso and Verena Wäsch for excellent technical assistance.
Contributors Design of the study: $Y Z, J H W D$. Acquisition of data: $Y Z, C D, C B$, $\mathrm{N}-\mathrm{YL}, \mathrm{AD}, \mathrm{PA}, \mathrm{KPZ}$. Interpretation of data: $Y Z, C D, C B, O D, G S$, JHWD. Manuscript preparation: YZ, PZ, LS, AK, OD, GS, JHWD. Provided patient samples: LS, AK.

Funding Grants DI 1537/4-1, DI 1537/5-1, DI 1537/7-1, BE 5191/1-1, AK 144/ 1-1 and SCHE 1583/7-1 of the Deutsche Forschungsgesellschaft, grants A40 and $\mathrm{J} 29$ of the IZKF in Erlangen, the ELAN-Program of the University of

Erlangen-Nuremberg and the Career Support Award of Medicine of the Ernst Jung Foundation.

Competing interests $O D$ has consultancy relationships and/or has received research funding from Actelion, Pfizer, Ergonex, BMS, Sanofi-Aventis, United BioSource Corporation, medac, Biovitrium, Boehringer Ingelheim, Novartis, 4D Science and Active Biotec in the area of potential treatments of scleroderma; JHWD has consultancy relationships and/or has received research funding from Actelion, Pfizer, Ergonex, BMS, Celgene, Bayer Pharma, Boehringer Ingelheim, JB Therapeutics, Sanofi-Aventis, Novartis, Array Biopharma and Active Biotec in the area of potential treatments of scleroderma and is stock owner of $4 D$ Science $\mathrm{GmbH}$. AK has consultancy relationships and/or has received reasearch founding from Actelion, MEDA Pharma and Pfizer.

Ethics approval University of Erlangen-Nuremberg.

Provenance and peer review Not commissioned; externally peer reviewed.

\section{REFERENCES}

1 Gabrielli A, Avvedimento EV, Krieg T. Scleroderma. N Engl J Med 2009;360:1989-2003.

2 Tyndall AJ, Bannert B, Vonk $M$, et al. Causes and risk factors for death in systemic sclerosis: a study from the EULAR Scleroderma Trials and Research (EUSTAR) database. Ann Rheum Dis 2010;69:1809-15.

3 Samarakoon R, Overstreet JM, Higgins PJ. TGF-beta signaling in tissue fibrosis: redox controls, target genes and therapeutic opportunities. Cell Signal 2013;25:264-8

4 Duncan JS, Litchfield DW. Too much of a good thing: the role of protein kinase CK2 in tumorigenesis and prospects for therapeutic inhibition of CK2. Biochim Biophys Acta 2008;1784:33-47.

5 Litchfield DW. Protein kinase CK2: structure, regulation and role in cellular decisions of life and death. Biochem J 2003;369(Pt 1):1-15.

6 Montenarh M. Cellular regulators of protein kinase CK2. Cell Tissue Res 2010;342:139-46.

7 Landesman-Bollag E, Romieu-Mourez R, Song DH, et al. Protein kinase CK2 in mammary gland tumorigenesis. Oncogene 2001;20:3247-57.

8 Yenice S, Davis AT, Goueli SA, et al. Nuclear casein kinase 2 (CK-2) activity in human normal, benign hyperplastic, and cancerous prostate. Prostate 1994;24:11-16.

9 Daya-Makin M, Sanghera JS, Mogentale TL, et al. Activation of a tumor-associated protein kinase (p40TAK) and casein kinase 2 in human squamous cell carcinomas and adenocarcinomas of the lung. Cancer Res 1994;54:2262-8.

10 Faust RA, Gapany M, Tristani P, et al. Elevated protein kinase CK2 activity in chromatin of head and neck tumors: association with malignant transformation. Cancer Lett 1996;101:31-5.

11 Stalter G, Siemer S, Becht E, et al. Asymmetric expression of protein kinase CK2 subunits in human kidney tumors. Biochem Biophys Res Commun 1994;202: $141-7$.

12 Brown MS, Diallo OT, Hu M, et al. CK2 modulation of NF-kappaB, TP53, and the malignant phenotype in head and neck cancer by anti-CK2 oligonucleotides in vitro or in vivo via sub-50-nm nanocapsules. Clin Cancer Res 2010;16:2295-307.

13 Siddiqui-Jain A, Drygin D, Streiner N, et al. CX-4945, an orally bioavailable selective inhibitor of protein kinase CK2, inhibits prosurvival and angiogenic signaling and exhibits antitumor efficacy. Cancer Res 2010;70:10288-98.

14 Mazzorana M, Pinna LA, Battistutta R. A structural insight into CK2 inhibition. Mol Cell Biochem 2008;316:57-62.

15 Zheng Y, Qin H, Frank SJ, et al. A CK2-dependent mechanism for activation of the JAK-STAT signaling pathway. Blood 2011;118:156-66.

16 Dees C, Tomcik M, Palumbo-Zerr K, et al. JAK-2 as a novel mediator of the profibrotic effects of transforming growth factor beta in systemic sclerosis. Arthritis Rheum 2012;64:3006-15.

17 LeRoy EC, Medsger TA Jr. Criteria for the classification of early systemic sclerosis. J Rheumatol 2001;28:1573-6.

18 Khodzhigorova A, Distler A, Lang V, et al. Inhibition of sumoylation prevents experimental fibrosis. Ann Rheum Dis 2012;71:1904-8.

19 Akhmetshina A, Dees C, Pileckyte $M$, et al. Rho-associated kinases are crucial for myofibroblast differentiation and production of extracellular matrix in scleroderma fibroblasts. Arthritis Rheum 2008;58:2553-64.

20 Distler $\mathrm{JH}$, Jungel $\mathrm{A}$, Huber LC, et al. The induction of matrix metalloproteinase and cytokine expression in synovial fibroblasts stimulated with immune cell microparticles. Proc Natl Acad Sci U S A 2005;102:2892-7. 
21 Dees C, Schlottmann I, Funke R, et al. The Wnt antagonists DKK1 and SFRP1 are downregulated by promoter hypermethylation in systemic sclerosis. Ann Rheum Dis 2013.

22 Dees $\mathrm{C}$, Tomcik $\mathrm{M}$, Zerr $\mathrm{P}$, et al. Notch signalling regulates fibroblast activation and collagen release in systemic sclerosis. Ann Rheum Dis 2011;70:1304-10.

23 Reich N, Maurer B, Akhmetshina A, et al. The transcription factor Fra-2 regulates the production of extracellular matrix in systemic sclerosis. Arthritis Rheum 2010;62:280-90.

24 Beyer C, Skapenko A, Distler A, et al. Activation of pregnane X receptor inhibits experimental dermal fibrosis. Ann Rheum Dis 2013;72:621-5.

25 Reich N, Tomcik M, Zerr P, et al. Jun N-terminal kinase as a potential molecular target for prevention and treatment of dermal fibrosis. Ann Rheum Dis 2012;71:737-45.

26 Dees C, Akhmetshina A, Zerr P, et al. Platelet-derived serotonin links vascular disease and tissue fibrosis. J Exp Med 2011;208:961-72.

27 Palumbo K, Zerr P, Tomcik M, et al. The transcription factor JunD mediates transforming growth factor \{beta\}-induced fibroblast activation and fibrosis in systemic sclerosis. Ann Rheum Dis 2011;70:1320-6.

28 Avouac J, Furnrohr BG, Tomcik M, et al. Inactivation of the transcription factor STAT-4 prevents inflammation-driven fibrosis in animal models of systemic sclerosis. Arthritis Rheum 2011;63:800-9.

29 Beyer C, Schramm A, Akhmetshina A, et al. beta-catenin is a central mediator of pro-fibrotic Wnt signaling in systemic sclerosis. Ann Rheum Dis 2012;71:761-7.

30 Avouac J, Palumbo K, Tomcik M, et al. Inhibition of activator protein 1 signaling abrogates transforming growth factor beta-mediated activation of fibroblasts and prevents experimental fibrosis. Arthritis Rheum 2012;64:1642-52.

31 Beyer C, Schett G, Distler O, et al. Animal models of systemic sclerosis: prospects and limitations. Arthritis Rheum 2010;62:2831-44.
32 Distler A, Deloch L, Huang J, et al. Inactivation of tankyrases reduces experimental fibrosis by inhibiting canonical Wnt signalling. Ann Rheum Dis 2012.

33 Palumbo-Zerr K, Horn A, Distler A, et al. Inactivation of fatty acid amide hydrolase exacerbates experimental fibrosis by enhanced endocannabinoid-mediated activation of CB1. Ann Rheum Dis 2012;71:2051-4.

34 Kramer M, Dees C, Huang J, et al. Inhibition of H3K27 histone trimethylation activates fibroblasts and induces fibrosis. Ann Rheum Dis 2013;72:614-20.

35 Horn A, Kireva T, Palumbo-Zerr K, et al. Inhibition of hedgehog signalling prevents experimental fibrosis and induces regression of established fibrosis. Ann Rheum Dis 2012;71:785-9.

36 Tomcik M, Zerr P, Pitkowski J, et al. Heat shock protein 90 (Hsp90) inhibition targets canonical TGF-beta signalling to prevent fibrosis. Ann Rheum Dis 2013.

37 Weingartner $\mathrm{S}$, Zerr $\mathrm{P}$, Tomcik $\mathrm{M}$, et al. Pomalidomide is effective for prevention and treatment of experimental skin fibrosis. Ann Rheum Dis 2012;71:1895-9.

38 Akhmetshina A, Venalis P, Dees C, et al. Treatment with imatinib prevents fibrosis in different preclinical models of systemic sclerosis and induces regression of established fibrosis. Arthritis Rheum 2009;60:219-24.

39 Akhmetshina A, Palumbo K, Dees C, et al. Activation of canonical Wnt signalling is required for TGF-beta-mediated fibrosis. Nat Commun 2012;3:735.

40 Beyer $\mathrm{C}$, Reichert $\mathrm{H}$, Akan $\mathrm{H}$, et al. Blockade of canonical Wnt signalling ameliorates experimental dermal fibrosis. Ann Rheum Dis 2013.

41 Beyer C, Reich N, Schindler SC, et al. Stimulation of soluble guanylate cyclase reduces experimental dermal fibrosis. Ann Rheum Dis 2012;71:1019-26.

42 Song DH, Dominguez I, Mizuno J, et al. CK2 phosphorylation of the armadillo repeat region of beta-catenin potentiates Wnt signaling. J Biol Chem 2003:278:24018-25.

43 Cozza G, Pinna LA, Moro S. Kinase CK2 inhibition: an update. Curr Med Chem 2013:20:671-93. 


\section{ARD Inhibition of casein kinase II reduces TGF $\beta$ induced fibroblast activation and ameliorates experimental fibrosis}

Yun Zhang, Clara Dees, Christian Beyer, Neng-Yu Lin, Alfiya Distler, Pawel Zerr, Katrin Palumbo, Laura Susok, Alexander Kreuter, Oliver Distler, Georg Schett and Jörg H W Distler

Ann Rheum Dis 2015 74: 936-943 originally published online January 15, 2014

doi: 10.1136/annrheumdis-2013-204256

Updated information and services can be found at:

http://ard.bmj.com/content/74/5/936

These include:

Supplementary Material

References

Email alerting service
Supplementary material can be found at:

http://ard.bmj.com/content/suppl/2014/01/15/annrheumdis-2013-2042 56.DC1.html

This article cites 39 articles, 20 of which you can access for free at: http://ard.bmj.com/content/74/5/936\#BIBL

Receive free email alerts when new articles cite this article. Sign up in the box at the top right corner of the online article.

\section{Notes}

To request permissions go to:

http://group.bmj.com/group/rights-licensing/permissions

To order reprints go to:

http://journals.bmj.com/cgi/reprintform

To subscribe to BMJ go to:

http://group.bmj.com/subscribe/ 